\title{
PORE STRUCTURE OF CONCRETE AND FREEZING VULNERABILITY
}

Robert E. Philleo

Conculting Engineer

7420 Annanwood Court

Annandale, VA 22003

\section{James $R_{\text {. Clifton }}$}

U.S. DEPARTMENT OF COMMERCE National Institute of Standards and Toehnology

National Englneering Laboratory Center for Bulldlng Tochnology Bullding Materials Division Calthorcburg, MD 20899

U.S. DEPARTMENT OF COMMERCE Robert A. Mosbacher, secretary NATIONAL INSTIUTE OF STANDARDS AND TECHNOLOCY

Raymond C. Kammer, Acting Dlrector

$-Q C$

100

.456

89-4186

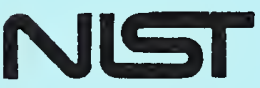

1989

C. 2 
NATIONAL INSTITUTE OF STANDARDS \& TECHNOLOGY

Research Information Center

Gaithersburg, MD 20899 


\section{PORE STRUCTURE OF CONCRETE AND FREEZING VULNERABILITY}

\section{Robert E. Philleo}

Consulting Englineer 7420 Annanwood Court Annandale, VA 22003

\section{James R. Clifton}

U.S. DEPARTMENT OF COMMERCE Natlonal Institute of Standards and Tochnology National Englneering Laboratory Center for Bullding Technology Bullding Matorlals Division Galthorsburs, MD 20898

November 1989

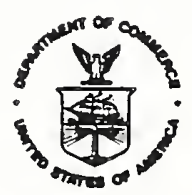

U.S. DEPARTMENT OF COMMERCE Robert A. Mosbacher, Socretary MATHONAL INSTITUTE OF STANDARDS AND TECHNOLOCY

Raymond a. Kammer, Aeting Diroctor 
High-performance concrete with water-to-cement ratio (w/c) of or below 0.38 , when hydrated to the maximum possible level, should not contain any freezeable water. Therefore, non-air-entrained concrete with such $\mathrm{w} / \mathrm{C}$ should be immune to freezing. However, laboratory freezing and thawing studies on non-air-entrained concretes containing silica fume have given conflicting results. Reasons for the conflicting results are explored in this report by analyzing relationships between w/c, capillary porosity, and freezable water in concretes with low w/c's. The effects of adding silica fume to concrete on potential frost damage is also discussed.

KEYWORDS: Concrete; Durability; Entrained-air; Freezing and thawing; High-performance concrete; Silica fume; Water-to-cement ratio. 



\section{INTRODUCTION}

Recent advances in concrete technology has resulted in the development of high-performance concrete with low water-to-cement ratios $(w / c)$. The two principal advances involve the use of superplasticizers (high-range-water-reducing admixtures) which permit the placement of concrete of very low w/c, and silica fume, a pozzolan of extremely high fineness. The advent of this high-performance concrete has resulted in controversy over the need for entrained air in such concrete (1).

The resistance of concrete to freezing is dependent on its capacity for and its probability of containing freezable water. Even the strongest concrete now in use cannot withstand the hydraulic pressure of more than $205 \mathrm{MPa}$ generated by the freezing of water (1). Concrete of commonly used W/C's usually has a capacity for freezable water, even at complete hydration. Therefore, if it is anticipated that the concretes will be exposed to water and freezing temperatures, they are usually protected by the addition of air entrained admixtures.

It has been suggested (1) that low w/c concretes (below 0.38 , by mass), if properly cured, will not have a capacity for freezable water or will not become critically saturated with water and thus do not need entrained air to resist freezing and thawing damage. Studies by Malhotra $(2,3)$ indicate that low w/c non-air-entrained concretes are not durable when tested according to ASTM C 666

(4). Kashi and Weyers (5) found that non-air-entrained concretes with w/C below 0.3 passed the ASTM C 666 test. Yamato and Emotov reported (6) that non-air-entrained concrete containing silica fume and having a water-to-cement ratio (w/c) of 0.25 is immune to freezing and thawing damage, while similar concrete with w/C above 0.25 needed entrained-air.

In the present report, relationships between w/c, capillary porosity, and freezable water in concrete are analyzed for concretes with low w/c's. The effects of adding silica fume to concrete on potential frost damage is also discussed.

\section{FREEZING AND THAWING PROCESS}

Water expands nine percent when it freezes. When freezing takes place in a confined space, pressures as high as $200 \mathrm{MPa}(29,000$ psi) may develop (7). While there is still some controversy as to the exact mechanism of stress development in concrete during freezing, there is agreement that the stress develops from the movement of water through the small pores in concrete and not from direct ice crystal pressure, except in very young concrete or very porous mature concrete where ice lenses similar to those seen in soils may form (8). During freezing of water in 
concrete, it has been proposed that water moves under hydraulic pressure generated by an expanding ice mass, by diffusion induced thermodynamically by the flow of unfrozen water in small pores to ice forming in larger pores, or by osmotic pressure forcing water with a relatively high concentration of dissolved salts toward an ice mass with a very small salt concentration (9). All of these phenomena are probably present and are adequately dealt with by an adequate air void system in the concrete, or more properly, in the cement-paste phase of the concrete. As water is forced through the pores, pressure builds up as a function of path length. Air voids, which are so large as to constitute an interruption of the porous system, provide an end to the water path by providing an outlet for water forced in by the freezing process. If the air voids are adequately spaced, they shorten the paths for the water flow to lengths which will not cause disruptive pressures. Freezing will continue at a given temperature unless the pressure on the ice reaches the maximum pressure under which ice can exist at that temperature. The pressure varies from one atmosphere at $0^{\circ} \mathrm{C}$ to $200 \mathrm{MPa}$ at $-20^{\circ} \mathrm{C}$ (8). The pressure is developed by water adjacent to the ice, which is compressed by the expanding ice mass and which cannot escape fast enough to relieve the pressure. Normal strength concrete has only the strength to withstand freezing at about $-I^{\circ} \mathrm{C}$. Thus, concrete that may be expected to be frozen in a moist environment must contain entrained air unless it has sufficient tensile strength to withstand the freezing pressures or it contains no freezable water. Although concrete strengths have escalated, even high-strength concrete cannot yet withstand freezing pressures (1). Therefore, at present the only means for producing a durable non-air-entrained concrete is to produce a concrete having no freezable water.

\section{FREEZABLE WATER}

An obvious approach to a water-free concrete is to desiccate structures in place after construction. Building frames, which dry out in service, have proven to be durable when made from non-air-entrained concrete. They lose water to the atmosphere and have no source of re-wetting other than an occasional rain, which produces only a superficial surface wetting that is quickly lost during subsequent drying. Unfortunately, concrete in many other exposures cannot dry by natural processes sufficiently to make them immune to freezing. For example, pavement slabs lie in a horizontal position, which makes the effect of rainfall much more severe than in a vertical building frame. Such slabs also continually pick up moisture from the subgrade. Perhaps the most severe exposure is a navigation lock operated in freezing temperatures. Concrete under a head of as much as 30 meters may suddenly have the head removed and be exposed to a freezing temperature with no opportunity for drying. Tidal structures in cold climates suffer a milder form of this same type of exposure. 
In principle, structures in these adverse environments could be desiccated and sealed, but no satisfactory technique has been developed. The only plausible approach is to manipulate the microstructure so that freezable water is excluded from

the concrete.

Before freezable water can be discussed, it must be defined. The logical definition that it is the water that will freeze when the temperature drops to a particular value is used herein. In concrete which has reached any significant degree of maturity, water is contained in small pores. Whether water will freeze at a given temperature depends on the diameter of the pore in which it is contained. The smaller the pore size, the lower the temperature must drop to produce freezing. Helmuth (8) has quantified the relationship, taking into account the size of the smallest ice crystal that is stable at the selected temperature and the layer of water adsorbed on the inner surface of the pore. The size of the ice crystal was taken from the work of Volmer (10). The adsorbed layer was taken to about four monolayers of water based on the work by Powers and Brownyard (11), although the exact thickness varies slightly as a function of temperature. The dependence of the freezing temperature on pore size is shown in table 1 .

Thus, the definition of freezable water in a porous system is a function of temperature and pore size. For example, If concrete is to be durable down to a temperature of $-20^{\circ} \mathrm{C}$, it must contain no significant number of pores larger than 3.5 nanometers in diameter. If larger pores are to be tolerated, either the concrete must be protected from very low temperatures or it must be air entrained.

\section{WATER REQUIRED FOR HYDRATION}

Concrete consists of about three-quarters aggregate and one-quarter cement paste. Only the cement-paste constituent will be considered here. Aggregate, by its sheer bulk, makes an important contribution to concrete durability. Iike cement paste, it has an internal pore system which, if unfavorable may contribute to popouts or d-cracking; but once the aggregate is selected, aggregate properties are beyond the control of the concrete technologist, except that occasionally a problem may be corrected by reducing the size of the coarse aggregate (12).

Cement paste properties are very much within the control of the concrete technologist. The structure of portland cement paste was first detailed by Powers and Brownyard (11). The Powers model, although it was limited by their lack of apparatus to measure actual pore-size distribution, is still the most widely-accepted model of hardened cement paste. Their investigation $y$ ielded the following important observations: 
(1) When a unit volume of cement hydrates, it produces 2.2 volumes of hydrated material.

(2) The hydrated material, commonly called gel because of its colloidal nature, has an inherent porosity of about 26 percent.

(3) Because of the small size of the gel pores, they attract any water that is available, and when the water enters the pores, since much of it is adsorbed water rather than free water, it has a specific volume of about 0.9 .

These observations, combined with the knowledge that a unit mass of a typical portland cement combines with 0.22 unit mass of water in the hydration reaction (11), make it possible to construct a physical model of a cement paste of any water-cement ratio at any degree of hydration. It is apparent, for example, that a water-cement ratio of 1.2 by volume is a critical value. since the only place that hydration products can form is in the space originally occupied by cement and water (the rest being unyielding aggregate) a knowledge of water-cement ratio provides all the information needed to determine the space available for hydration products. With a water-cement ratio of 1.2 by volume the total 2.2 volume of combined cement and water provide just enough room to hydrate all the cement with no space left over and no cement left unhydrated. The water-cement ratio is normally expressed by mass and the water-cement ratio of 1.2 by volume can be converted to a mass ratio by dividing it by 3.15 , the specific density of most portland cements (13), to yield a value of 0.38 .

If the water-cement ratio exceeds 0.38 by mass, even after complete hydration, there will be unfilled space in the original cement-and-water-filled space. As hydration continues, this space tends to be subdivided into isolated pockets called capillary pores by Powers to distinguish them from the gel pores inherent in the hydrated product (table 2). If the water-cement ratio is below 0.38 , there simply is insufficient room, as well as insufficient water, to hydrate all the cement and thus some cement must remain unhydrated. If hydration proceeds until all the space is filled, then a concrete without capillary porosity is achieved.

Powers lacked the equipment for determining the size distribution of the pores. For many purposes, it would undoubtedly be beneficial to know the size distribution, but he reasoned that for durability in a freezing environment it was unnecessary. He observed in experiments with temperatures lowered to $-20^{\circ} \mathrm{C}$ that water in gel pores did not freeze: water in capillary pores did freeze (11). Thus, it was reasonable to conclude, based on table 1, that gel pores had a diameter less than $3.5 \mathrm{~nm}$ and that 
capillary pores were larger. He assumed a bimodal distribution of big pores and little pores.

In the following, the amount of water required for hydration of portland cement is analyzed in more detail. Consider what happens when one kilogram of cement hydrates according to the calculations in table 3. These calculations and the below following discussion are based om an ideal case where the cement and water are completely intermixed. Therefore, $0.42 \mathrm{~kg}$ of water is required to hydrate $1.00 \mathrm{~kg}$ of cement, even though only 0.22 $\mathrm{kg}$ of water enters into chemical reaction as each unit of cement hydrates. However, the gel pore structure draws in some of the mix water and makes it unavailable for further reaction. As long as the water-cement ratio exceeds 0.42 , there is no problem. Hydration will go to completion because excess water is available and the volume of the capillary porosity may be calculated as indicated above. At lower water-cement ratios there is a potential problem. Cement hydration will be interrupted unless water can be supplied from the outside. With a water-cement ratio of 0.38 , for example, without outside water hydration will cease when only 90 percent of the available space is filled. A water quantity of $0.38 \mathrm{~kg}$ is capable of hydrating only .90 $\mathrm{kg}$ of cement. instead of completely filling the space, the hydration process stops with a capillary porosity of 10 percent unless additiogd water can be provided. This process of running out of water 1 s usually referred to as "self-desiccation." For all water-cement ratios less than 0.38 , likewise there will be a capillary porosity of 10 percent in the absence of outside water. The problem may actually be somewhat worse than stated. Hydration proceeds only in an atmosphere with a high humidity. Various investigators place the minimum relative humidity to sustain hydration at values in the range of 70 to 80 percent (13). Cement in the interior portion of concrete, remote from the outside atmosphere, may cease to hydrate before the capillaries are completely emptied of water if the available water drops below the level necessary to sustain the required vapor pressure.

\section{EFFECTS OF MINERAL ADMIXTURES}

The Powers' work is outmoded chiefly by its inability to quantify pore sizes and by its lack of inclusion of many materials, other than portland cement and water, which are now commonly found in cement paste. These chiefly are high-range water-reducing admixtures, fly ash, blast-furnace slag, and silica fume. High-range water reducers, by theirselves, produce essentially the same pore structure at a given water-cement ratio as cement paste without the admixture (14). Their advantage is that they extend the water-cement ratio of practical concrete to low value previously considered impossible. Fly ash, and to a lesser extend blast-furnace slag, reduces the amount of calcium 
hydroxide in hydrated cement paste with a concomitant increase in the amount of calcium-silicate-hydrate, but the pore structure, at a give water-to-solids (amount of cement and mineral admixture), ratio does not change appreciably (1).

The only commonly-used material which produces a significant change in pore structure is silica fume (I). The nature of the capillary porosity must be related to the particle sizes of the granular material in the solid phase of the cement paste. If all the particles were reduced in size by one half, the second system would become a scale model of the first, and the pores could be expected to be half as large. This generalization is not quite accurate because the size of the molecules participating in and formed by the reactions does not scale, and some of the smaller pores approach molecular dimensions: but the illustration is adequate as a first approximation. Fly ash and slag have particle sizes about the same as portland cement, but silica fume particles are two orders of magnitude smaller than those of cement. As may be expected, silica fume produces capillary pores much finer than those in a cement paste without silica fume. The pore size distributions, as determined by mercury porosimetry, for cement pastes having a water-cement ratio of 0.45 , with 0 , 10, and 30 percent replacements of cement with silica fume are presented in Fig. 1 (15). The futility of expressing water-cement ratio by mass becomes apparent in dealing with these blending materials since their densities differ from that of portland cement. An analysis of the curve for normal portland cement paste indicates that there is no bimodal distribution as there is a continuous pore size distribution down to a few nanometers. Based on the Powers model, calculations for a completely-hydrated paste would predict a total porosity of 33 percent, of which 9 percent would be capillary porosity. At 180 days the experimentally determined total porosity was 29 percent. This is rather good agreement since it is known that the mercury cannot penetrate all the voids. If 3.5 nanometers is taken as the boundary between gel and capillary pores, the observed capillary porosity is 13 percent, somewhat higher than the theoretical. However, if the boundary is moved to 4 nanometres, 9 , percent of the porosity would be classified as capillary pores for an exact agreement with theory. It may be concluded that the Powers model is essentially correct for portland cement, except that there is a continuum of pore sizes with no sharp demarcation between gel and capillary pores and that the transition between the two types of pores occurs in the vicinity of 4 nanometers.

The data for pastes containing silica fume are particularly interesting, as follows. The pastes with both levels of silica fume replacement, should contain 9 percent large pores, however they contain essentially no measurable pores. Large pores could exist which are isolate and thus are not accessible to mercury intrusion. With a 10 percent replacement the preponderance of pores is under 20 nanometers and for the 30 percent replacement 
under 10 nanometers. This observed phenomenon has produced confusion in the literature as to how to designate the pores. For example, should they be designated by origin, based on assuming that the capillary pores have been reduced to a very small size by the pozzolanic reaction of silica fume? Or should the pores should be classified by size, because it appears that using silica fume produces nothing but gel pores?

Based on theoretical considerations and laboratory test results it may be concluded that non-air-entrained concrete containing portland cement, or blends of portland cement with fly ash or slag, may be made frost resistant i) if the water-cement ratio does not exceed 1.2 by volume, $i i)$ if sufficient water is supplied from the outside to make up for the loss through self-desiccation, and $i$ ii) if the concrete is not exposed to freezing until all the original cement-and-water filled space is filled with hydration products. For concrete containing a blend of portland cement and silica fume requirements (ii) and iii) hold, although a somewhat higher water-cement ratio may be tolerated.

\section{FIELD CONCRETE CONSIDERATIONS}

Pitfalls in applying these theoretical and laboratory conclusions to field concrete of low $\mathrm{w} / \mathrm{c}$ ratio include the time required to complete hydration and the near-impossibility of supplying extra water to the interior of the concrete. Traditionally, one of the heralded advantages of concrete has been the relatively slow rate of hydration of portland cement. It could be justifiably claimed that structures became stronger in service as they aged. Cements have become more rapid strength gainers during the past generation in response to market demands and to the dismay of many sophisticated users (16), but these same users may now demand even faster hydrating cements if frost-resistant structures are to be put in service at an economically reasonable age.

An even greater problem is the need for additional curing water. If free of cracks and of uniform microstructure, the interior of a large high-strength structural member could be essentially a sealed system. Then as the concrete is cured, the exterior layer, to which water can be accessible, becomes so impermeable that it is virtually impossible, except under high head, to force water into the interior. In a laboratory moist room, however, small specimens which have most of their volume near a surface can realize the benefit of added water. An experience on a recently completed building in seattle is revealing. Concrete having a strength as high as $130 \mathrm{MPa}$ was used. The highest strength concrete was used in building columns for for reasons of stiffness rather than strength. Thus, there was a great deal of interest in tests for modulus of elasticity. Tests run on 150 by 
$300 \mathrm{~mm}$ cylinders failed to meet the required value for modules of elasticity. When the laboratory switched to 100 by $200 \mathrm{~mm}$ specimens, results were satisfactory (17). The importance of the accessibility of outside water is well demonstrated.

Incidentally, the high-strength columns were surrounded by a steel jacket so that moist curing even of the surface was impossible. High-strength structural elements have consistently failed to match laboratory results when cores have been removed and tested for strength. The strength deficiency has commonly been attributed to thermal effects, but a significant part of it may be the result of the different degrees of hydration through the concrete thickness.

There is a legitimate question as to how serious an effect the lack of complete hydration has on durability. After all, if water to complete the hydration is unable to penetrate the concrete, water which might damage the concrete on freezing also cannot get in. The interior is dry as a result of self-desiccation. Such a conclusion is probably justified in the case of building elements. In buildings, the failure to reach design levels of strength and stiffness is a more serious problem than the failure to eliminate capacity for freezable water. The situation for structures subjected to hydraulic head and structures on the ground is not as clear. Here, over time, water may penetrate beyond the surface. If water enters the interior at a faster rate than the hydration process can use it, there may be a net quantity of freezable water in the concrete, which could be vulnerable to freezing, depending on the size of the pores. certainly, any concrete that is gaining strength potentially contains freezable water.

Most of the knowledge needed to deal with the relationship between pore structure and freezing vulnerability is in hand. But the inconclusive results obtained on silica fume concretes in freezing and thawing testing suggest that some refinement is in order.

\section{SUMMARY}

Conventional concretes have a capacity for freezable water and are protected against freezing and thawing damage by the incorporation of entrained air. High-performance concretes with $w / c$ below 0.38 , if hydrated to the maximum level, should not contain any freezable water. However, several studies have indicated that concretes with $\mathrm{w} / \mathrm{C}$ below 0.38 and containing silica fume do not pass the commonly-used freeze-thaw test, ASTM C 666 .

At a $w / C$ of 0.38 sufficient space is available for the hydration products. If the $\mathrm{w} / \mathrm{C}$ is higher than 0.38 then capillary pores will be formed. However, if the $\mathrm{w} / \mathrm{C}$ ratio is below 0.42 
insufficient water is available to completely hydrate the cement. For example at a w/c of 0.38 at maximum hydration only $90 \%$ of the cement can be hydrated and $10 \%$ capillary porosity will be present. Unless exterior water can penetrate the cement paste, the capillary pores should not contain any water. When silica fume is added to cement and the $\mathrm{w} / \mathrm{C}$ is below 0.38 the resulting capillary pores are reduced to the size of gel pores. Therefore, non-air-entrained concretes with $\mathrm{w} / \mathrm{C}$ below 0.38 should be immune to freezing and thawing damage. If freezing and thawing damage does occur in non-air-entrained concrete, with silica fume and $w / C$ below 0.38 , it indicates that the maximum hydration has not taken place and freezable water is present.

Based on theoretical considerations from the Powers model and laboratory test results, it may be concluded that non-air-entrained concrete containing portland cement, or blends of portland cement with fly ash or slag, may be made frost resistant i) if the water-cement ratio does not exceed 1.2 by volume, $i i)$ if sufficient water is supplied from the outside to make up for the loss through self-desiccation, and iii) if the concrete is not exposed to freezing until all the original cement and water filled space is filled with hydration products.

Most of the knowledge needed to deal with the relationship between pore structure and freezing vulnerability is in hand. But the inconclusive results obtained on silica fume concretes in freezing and thawing suggest that some refinement is needed.

\section{REFERENCES}

1. R.E Philleo, "Freezing and Thawing Resistance of HighStrength Concrete," National Cooperative Highway Research Program Synthesis of Highway Practice No. 129 (1986).

2. V.M. Maholtra, K.A. Painter, and A. Silodeau, "Mechanical Properties and Freezing and Thawing Resistance of HighStrength Concrete Incorporating Silica Fume," Cement, concrete, and Aggregate, ASTM pp. 65-79 (1987).

3. V.M. Maholtra, "Mechanical Properties, and Freezing-andThawing Resistance of Non-Air-Entrained Condensed Silica-Fume Concrete using ASTM C 666, Procedure A and B," in Fly Ash, Silica Fume, and Natural Pozzolans in Concrete, ACI SP-91, pp 1069-1094 (1986).

4. Standard Test Method for Resistance of Concrete to Rapid Freezing and Thawing, ASTM Designation C 666. 
5. M.G. Kashi and R.E Weyers, "Freezing and Thawing Durability of High Strength Silica Fume Concrete," in Proceedings of Structural Materials, ASCE Structural Congress, pp. 138-148 (May, 1989).

6. T. Yamato and S.M. Emotov, "Strength and Freezing and Thawing Resistance of Concrete Incorporating Condensed silica Fume," in Fly Ash, Slag, Silica Fume, Slag, and Natural Pozzolans in Concrete, ACI SP-91, pp 1095-1117 (1986).

7. N.E Dorsey, "Properties of ordinary Water Substances," Rheinhold Publishing Corporation, 1940, p. 467.

8. R.A. Helmuth, "Capillary Size Restrictions on Ice Formation in Hardened Portland Cement Pastes," Chemistry of Cement, Proceedings of the Fourth International symposium, Washington, D.C., 1960, NBS monograph 43, Vol. 11, pp. 855-869.

9. G. Fagerlund, "Prediction of the service life of concrete Exposed to Frost Action," in Studies on Concrete Technology, Swedish Cement and Concrete Research Institute (1978).

10. M. Volmer, "Kinetic der Phasenbildung," Theodor Steinkoff, Dresden and Leipzig (1939).

11. T.C. Powers and T.L. Brownyard, "Studies of the Physical Properties of Hardened Portland Cement Paste," Journal of the American Concrete Institute, October-December, 1946 ;

January-Apri1, 1947, pp. 101-132, 249-336, 469-504, 549-602, $669-712,845-880,933-992$.

12. Guide to Durable Concrete, ACI Report $201.2 \mathrm{R}-77$ (1977).

13. S. Mindness and F. Young, "Concrete," Prentice-Hall, Inc. (Englewood, NJ, 1981).

14. G.G Litvan, "Air Entrainment in the Presence of Superplasticizers," Journal of" American Concrete Institute, Vol. 80 , No. 4, July-August 1983, pp. 326-331.

15. R.F. Feldman, and H. Cheng-yi, "Properties of Portland Cement-silica Fume Pastes. 1. Porosity and Surface Properties," Cement and Concrete Research, Vol. 15, No 5, 1985, pp. 765-774.

16. A. Neville, "Why We Have Concrete Durability Problems," in Concrete Durability, ACI SP-100, Vol. 1, pp. 21-30 (1987)

17. Discussion at ACI Forum on High-strength Concrete, ACI Spring Meeting, Atlanta (1989). 
Table 1. Relationship between Pore Size and Freezing Temperature (8).

Size of pore required for

Temperature ice formation at the select temperature

$$
\begin{array}{r}
\cdot C \\
\hline-2 \\
-6 \\
-10 \\
-15 \\
-20
\end{array}
$$

\begin{tabular}{r} 
nm \\
\hline 20.8 \\
8.3 \\
5.9 \\
4.4 \\
3.5
\end{tabular}


Table 2. Pore Classification (1).

\begin{tabular}{lc}
\hline Classification of Pore & Diameter \\
gel & $<1.2 \mathrm{~nm}$ \\
capillary & 1.2 to $1000 \mathrm{~nm}$ \\
entrained air & $>1000 \mathrm{~nm}$ \\
\hline
\end{tabular}



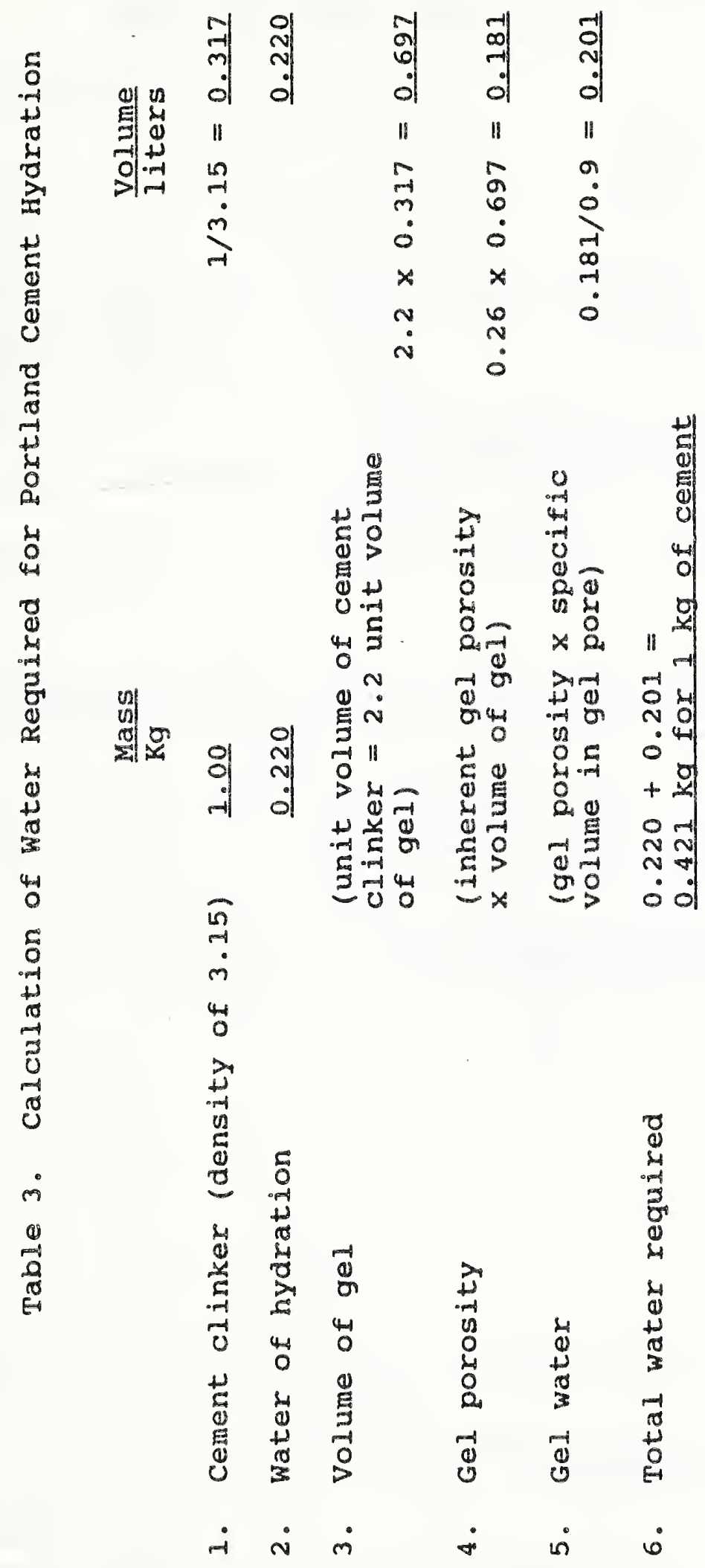


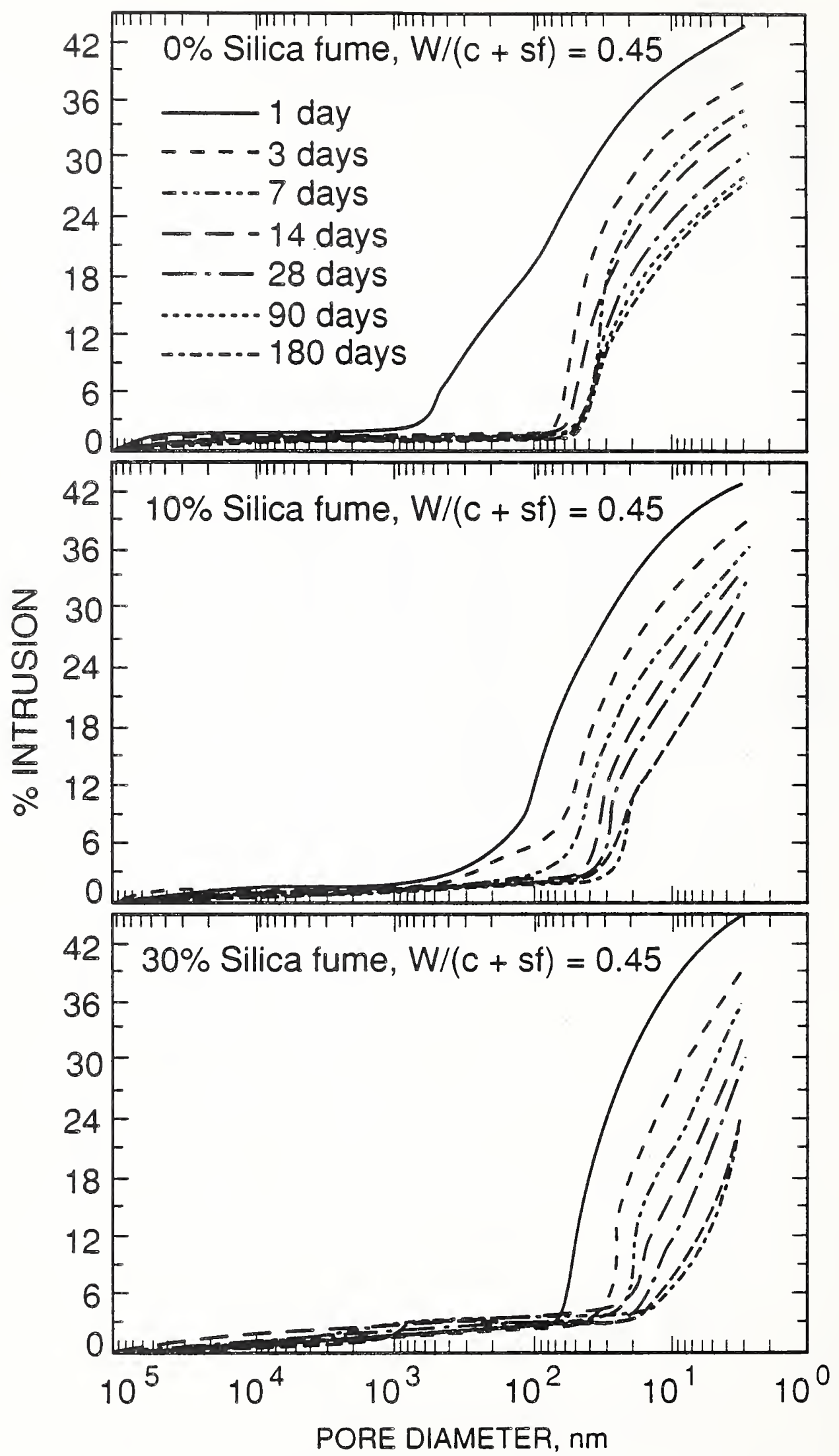

Figure 1. Pore-size distribution of cement pastes with and without silica fume (water-cement ratio $=0.45$ ) 
NIST-114A

(REV. 3-89)

NATIONAL INSTITUTE OF STANDARDS AND TECHNOLOGY

\section{BIBLIOGRAPHIC DATA SHEET}

1. PUBLCATION OR AEPORT MUMBER

NISTIR $89-4186$

2. PEAFOAMING ORGANIZATION REPOAT NUMBER

3. PUBLCATION DATE

NOVEMBER 1989

4. TITLE ANO SUBTITLE

Pore Structure of Concrete and Freezing Vulnerability

5. AUTHOR(S)

Robert E. Philleo and James R. Clifton

6. PEAFORMIMG ORGANIZATION (IF JOINT OR OTHEA THAN NIST, SEE INSTRUCTIONS)

U.S. DEPARTMENT OF COMMERCE

MATIOMAL INSTITUTE OF STANDARDS AND TECHNOLOGY

GAITHERSBURG, MD 20899

7. CONTRACT/GRANT NUMBER

8. TYPE OF AEPORT AND PERIOD COVEAED

9. SPONSORING ORQANIZATION NAME AND COMPLETE ADDAESS (STREET, CIT, STATE, ZIP)

NIST

Gaithersburg, MD 20899

10. SUPPLEMENTARY NOTES

DOCUMENT DESCRIBES A COMPUTER PROQRAM; SF-185, FIPS SOFTWARE SUMMARY, IS ATTACMED.

11. ABSTRACT (A 200-WORD OR LESS FACTUAL SUMMARY OF MOST SIGNIFICANT IMFORMATION. IF DOCUMENT INCLUDES A SIQMIFICANT BIBUOORAPHY OR LTTERATURE SURVEY, MENTION IT HERE.)

High-performance concrete with water-to-cement ratio (w/c) of or below 0.38 , when hydrated to the maximum possible level, should not contain any freezable water. Therefore, non-airentrained concrete with such w/c should be immune to freezing. However, laboratory freezing and thawing studies on non-air-entrained concretes containing silica fume have given conflicting results. Reasons for the conflicting results are explored in this report by analyzing relationships between $w / c$, capillary porosity, and freezable water in concretes with low w/c's. The effects of adding silica fume to concrete on potential frost damage is also discussed.

12. KEY WORDS (6 TO 12 ENTRIES; ALPHABETICAL ORDEA; CAPITALIE ONLY PROPEA MAMES; AMD SEPARATE KEY WOADS BY SEMICOLONS) concrete; durability; entrained-air; freezing and thawing; high-performance concrete; silica fume; water-to-water ratio.

13. AVAILABULTY

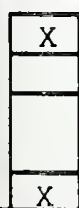

UNUMITED

FOR OfFICIAL DISTRIBUTION. DO NOT RELEASE TO NATIONAL, TECHNICAL INFORMATION SEAMCE (NTIS).

ORDER FROM SUPERINTENDENT OF DOCUMENTS, U.S. GOVERMMENT PAINTING OFFICE, WASHINOTON, DC 20402.

ORDER FROM MATIONAL TECHNICAL INFORMATION SERVCE (NTIS), SPRINGFIELD, VA 22161.
14. NUMBER OF PRINTED PAGES

18

15. PRICE

$\mathrm{AO} 2$ 


